\title{
Evaluasi Penerapan Smart Mobility di Jakarta
}

\section{(Evaluation of Smart Mobility Implementation in Jakarta)}

\author{
Sifa Novwidia Agni ${ }^{1}$, Manzila Izniardi Djomiy ${ }^{2}$, Roki Fernando ${ }^{3}$, Catur Apriono ${ }^{4}$
}

\begin{abstract}
Urban problems, such as congestion caused by rapid population growth and high urbanization, are common problems in Jakarta. The concept of a smart city has developed and began to be implemented in several major cities in Indonesia, including Jakarta. One part of the smart city concept is smart mobility, which is currently developing to solve various urban problems, especially in public transportation to improve the quality of effective and efficient services. This study discusses the solution of applying the concept of smart mobility in Jakarta based on the level of readiness of each indicator according to the indicators contained in the concept of the smart city. This paper aims to provide an overview of the level of smart mobility readiness implementation in the city of Jakarta, as well as the improvements that need to be done. This study uses a method of a literature study to get an early picture of conditions in Jakarta, then assessment using survey data assessment and qualitative analysis of descriptive. The results indicate that Jakarta is ready for the application of intelligent mobility. However, improvements and procurement in some aspects of intelligent mobility are deemed necessary.
\end{abstract}

Intisari-Masalah perkotaan, seperti kemacetan yang disebabkan olah pertumbuhan jumlah penduduk yang sangat pesat dan arus urbanisasi yang tinggi, menjadi masalah yang umum di kota besar seperti Jakarta. Konsep smart city sudah berkembang dan mulai diimplementasikan di beberapa kota besar di Indonesia, termasuk Jakarta. Salah satu bagian dari konsep smart city adalah smart mobility, yang saat ini berkembang untuk menyelesaikan berbagai masalah perkotaan, khususnya pada transportasi publik untuk meningkatkan kualitas layanan yang efektif dan efisien. Makalah ini membahas solusi penerapan konsep smart mobility di Jakarta berdasarkan tingkat kesiapan dari setiap indikatornya menurut indikator yang terdapat dalam konsep smart city. Tujuan makalah ini adalah untuk memberikan gambaran tentang tingkat kesiapan penerapan smart mobility di Jakarta serta perbaikan yang perlu dilakukan. Makalah ini menggunakan metode studi literatur untuk mendapatkan gambaran awal kondisi di Jakarta, lalu penilaian menggunakan assessment data survei serta analisis kualitatif dekskriptif. Hasilnya menunjukkan bahwa pada dasarnya Jakarta sudah siap dalam penerapan smart mobility, tetapi perlu ada perbaikan dan pengadaan di beberapa aspek smart mobility.

Kata Kunci-Smart Mobility, Jakarta, ICT, Indikator.

1,2.3,4 Departemen Teknik Elektro, Fakultas Teknik, Universitas Indonesia, Kampus Baru UI Depok, Jawa Barat, 16424, INDONESIA. (tlp:0274-555 225; e-mail: ${ }^{1}$ sifa.novwidia@ui.ac.id, ${ }^{2}$ manzila.izni@ui.ac.id,

${ }^{4}$ catur@eng.ui.ac.id)

\section{Pendahuluan}

Pertumbuhan jumlah penduduk di daerah perkotaan, khususnya kota besar, menimbulkan berbagai macam masalah, yang salah satunya adalah kemacetan. Provinsi DKI Jakarta sebagai ibu kota Indonesia tidak terlepas dari masalah kemacetan akibat semakin meningkatnya jumlah penduduk, tingkat kepadatan penduduk yang tinggi, serta urbanisasi yang tinggi yang membuat mobilitas penduduk dan kemacetan di Jakarta menjadi permasalahan setiap tahunnya. Salah satu penyebab kemacetan adalah meningkatnya jumlah kendaraan bermotor pribadi yang tidak sebanding dengan peningkatan panjang dan infrastruktur jalan. Akibatnya, jalan yang ada tidak mampu menampung volume kendaraan dan lalu lintas, terutama ketika jam sibuk.

Konsep yang saat ini sedang berkembang untuk area perkotaan adalah smart city. Menurut CNBC, smart city adalah konsep yang menanamkan teknologi ke dalam setiap aspek operasi, termasuk transportasi umum, konektivitas Information and Communication Technology (ICT), air, catu daya, sanitasi, pengelolaan limbah padat, mobilitas perkotaan, e-governance, dan partisipasi masyarakat [1]. Berdasarkan data Smart City Index 2020 dari International Institute for Management Development (IMD), kemacetan jalan dan polusi udra menjadi prioritas yang urgen di Jakarta [2].

Salah satu bagian dari konsep smart city adalah smart mobility. Beberapa penelitian yang fokus pada smart mobility telah dilakukan, seperti yang meneliti manfaat dari teknologi yang diimplementasikan serta memberikan solusi untuk mengoptimalkan pemanfaatan bus dan biaya operasional harian di Jakarta [3]. Lalu, penelitian mengenai penggunaan teknologi informasi pada Jakarta Smart City [4]. Referensi [5] menafsirkan topik smart mobility, dengan perhatian khusus pada penggunaan teknologi baru pada mobilitas perkotaan di Italia.

Salah satu penerapan smart mobility adalah pada transportasi publik. Jakarta memiliki bebagai macam moda transportasi publik, di antaranya kereta komuter (KRL), Bus Transjakarta (BRT), MRT, jaringan mikrobus Jaklingko, serta yang baru adalah LRT [6]-[10]. Namun, pemanfaatannya untuk mendorong masyarakat menggunakan transportasi publik agar dapat mengurangi penggunaan kendaraan pribadi sehingga dapat mengurangi kemacetan masih belum optimal [11]. Penggunaan teknologi dalam konsep smart mobility diharapkan dapat menjadikan transportasi publik menjadi lebih nyaman, aman, dan dapat diandalkan sehingga dapat lebih mendorong masyarakat beralih ke moda tranportasi publik [12]-[16].

Tujuan makalah ini secara umum adalah untuk memberikan evaluasi tentang tingkat kesiapan penerapan smart mobility di Jakarta serta seberapa jauh penerapan sudah dilakukan. 


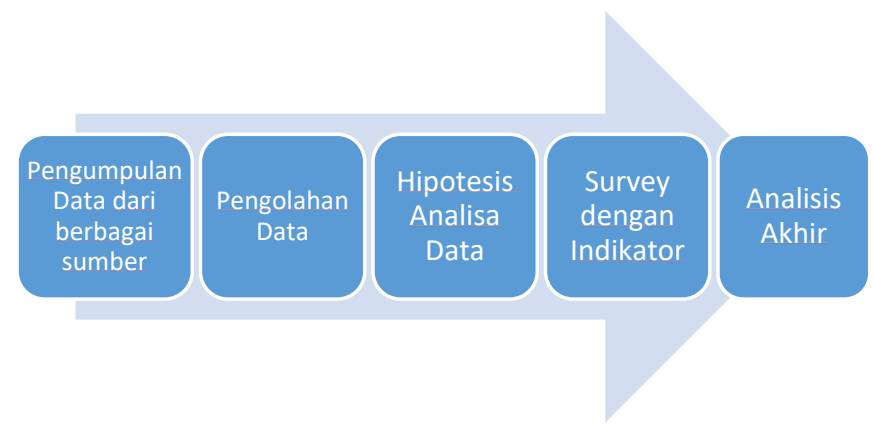

Gbr. 1 Metodologi penelitian.

Makalah ini memberikan masukan dan saran perbaikan yang diperlukan untuk memaksimalkan penerapan konsep smart mobility. Jakarta sebagai ibu kota negara diharapkan menjadi tolok ukur penerapan smart mobility yang baik di Indonesia.

\section{Metodologi}

Ruang lingkup penelitian dalam makalah ini adalah di wilayah DKI Jakarta. Lingkup pembahasan berfokus pada penerapan smart mobility pada transportasi publik di Jakarta. Metode penelitian yang digunakan adalah metode penelitian kualitatif deskriptif, dengan cara mengumpulkan data dari berbagai sumber dan membandingkan kemacetan Jakarta dengan kota-kota di negara lainnya. Gbr. 1 menunjukkan alur metodologi penelitian. Penelitian dilakukan dengan menggunakan data yang didapat dari berbagai sumber. Setelah data sekunder terkumpul, data diolah untuk mengetahui kondisi di Jakarta dan mendapatkan hipotesis awal. Lalu, dilakukan survei dengan indikator untuk menguatkan hipotesis sehingga didapatkan analisis akhir.

\section{A. Jenis Data}

Jenis data yang digunakan dalam makalah ini merupakan data publik dari Badan Pusat Statistik Jakarta [17], Badan Pemeriksa Keuangan [18], serta data pendukung dari lembaga internasional [19]. Kemudian, data diolah kembali untuk mendapatkan gambaran mengenai kondisi di Jakarta. Jenis data yang digunakan meliputi:

- panjang jalan,

- luas wilayah,

- jumlah penduduk,

- demografi usia penduduk,

- moda transportasi umum, dan

- jumlah kendaraan bermotor.

\section{B. Survei}

Untuk mengumpulkan dan menganalisis data, digunakan metode survei. Survei dilakukan untuk mengonfirmasi data yang telah didapatkan. Jenis-jenis pertanyaan survei kepada responden adalah sebagai berikut.

- Transportasi umum yang sering digunakan.

- Seberapa sering menggunakan transportasi umum.

- Alasan tidak menggunakan transportasi umum.

- Kondisi di moda transportasi MRT/KRL/LRT/BRT yang bersih.

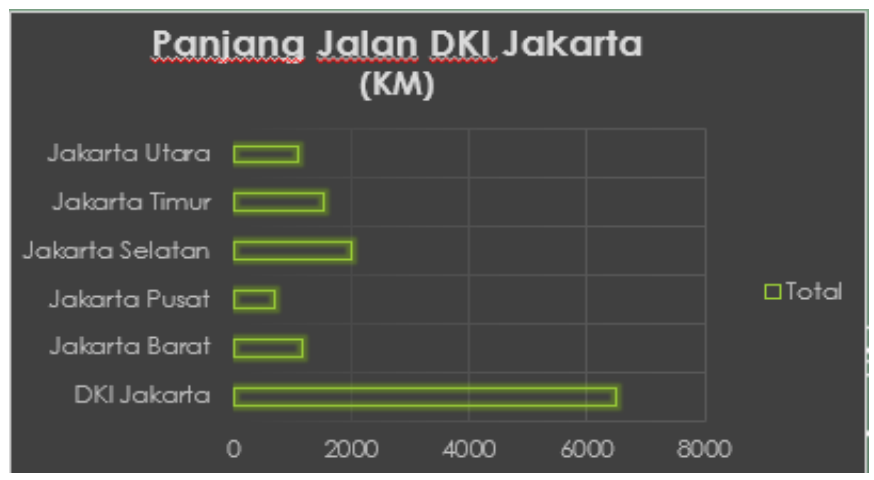

Gbr. 2 Panjang jalan Jakarta (sumber: bps.co.id).

\begin{tabular}{|c|c|}
\hline JAKARTA PUSAT & $47.90 \mathrm{KM}^{2}$ \\
\hline JAKARTA UTARA & $154.01 \mathrm{KM}^{2}$ \\
\hline JAKARTA BARAT & $126.15 \mathrm{KM}^{2}$ \\
\hline JAKARTA SELATAN & $145.73 \mathrm{KM}^{2}$ \\
\hline JAKARTA TIMUR & $187.73 \mathrm{KM}^{2}$ \\
\hline TOTAL & $661.5 \mathrm{KM} 2$ \\
\hline
\end{tabular}

Gbr. 3 Luas wilayah Jakarta (sumber: bps.co.id).

- Armada bus/kereta MRT/LRT/KRL/BRT berangkat tepat waktu.

- MRT/LRT/KRL/BRT telah memberikan informasi mengenai rute dan jadwal keberangkatan dan kedatangan melalui aplikasi.

- Transportasi online seperti Gojek/Grab selalu tersedia di sekitar stasiun.

- Membeli tiket atau kartu pembayaran top up praktis dan mudah dilakukan.

- Beralih antarmoda transportasi cukup mudah.

\section{HASIL DAN PEMBAHASAN}

Pengukuran smart mobility Jakarta dilakukan menggunakan indikator-indikator yang terdapat di dalam smart mobility [19]. Oleh karena itu, diskusi berfokus pada evaluasi kesiapan Jakarta dalam penerapan smart mobility dan melakukan assessment kepada pelanggan transportasi umum terhadap pengalamannya dalam menggunakan transportasi umum dengan disandingkan dengan data sekunder dari data-data publik yang sudah disediakan oleh website resmi, seperti jakarta.bps.go.id dan jakarta.bpk.go.id.

Gbr. 2 menunjukkan bahwa pada tahun 2019 jumlah panjang jalan di lima kota administrasi di Provinsi DKI Jakarta adalah $6.652 \mathrm{~km}$. Peningkatan pembangunan infrastruktur jalan bertujuan untuk mengurangi tingkat kepadatan lalu lintas kendaraan bermotor di provinsi DKI Jakarta. Lalu, Gbr. 3 menunjukkan bahwa luas wilayah Jakarta adalah $661.5 \mathrm{~km}^{2}$, yaitu 0,00012 lebih kecil dibanding luas wilayah Indonesia, dengan luas total wilayah Indonesia sekitar 7,81 juta $\mathrm{km}^{2}$.

Berdasarkan Sensus Penduduk (SP) 2020, jumlah penduduk Provinsi DKI Jakarta pada September 2020 sebanyak 10,56 juta jiwa, sedangkan jumlah penduduk Indonesia adalah 271,3 juta jiwa. Hal ini berarti sekitar 3\% dari penduduk yang ada di 


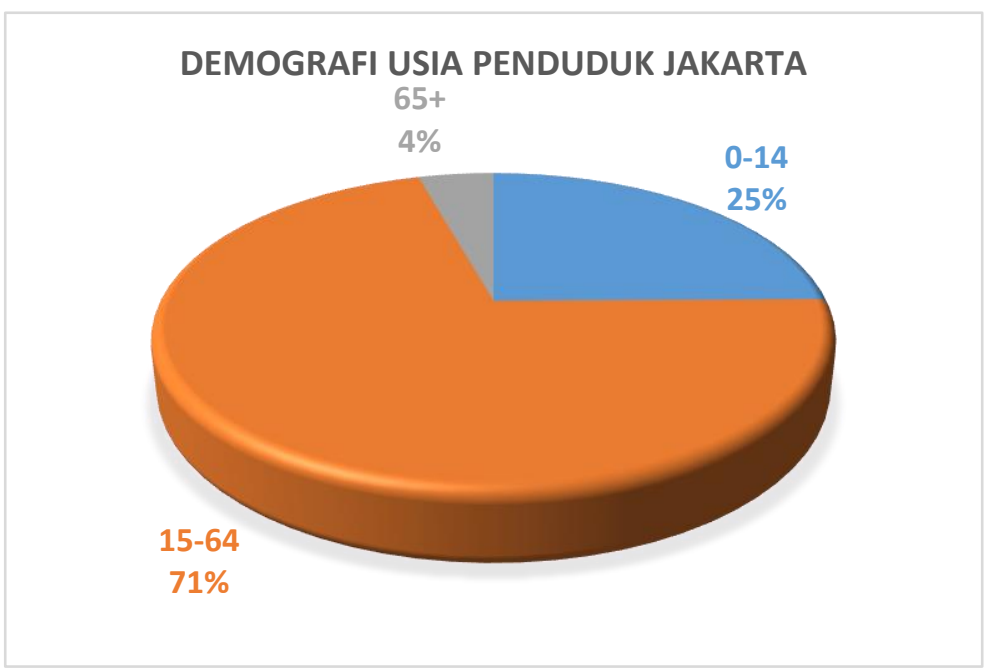

Gbr. 4 Demografi usia penduduk DKI Jakarta (sumber: bps.co.id).
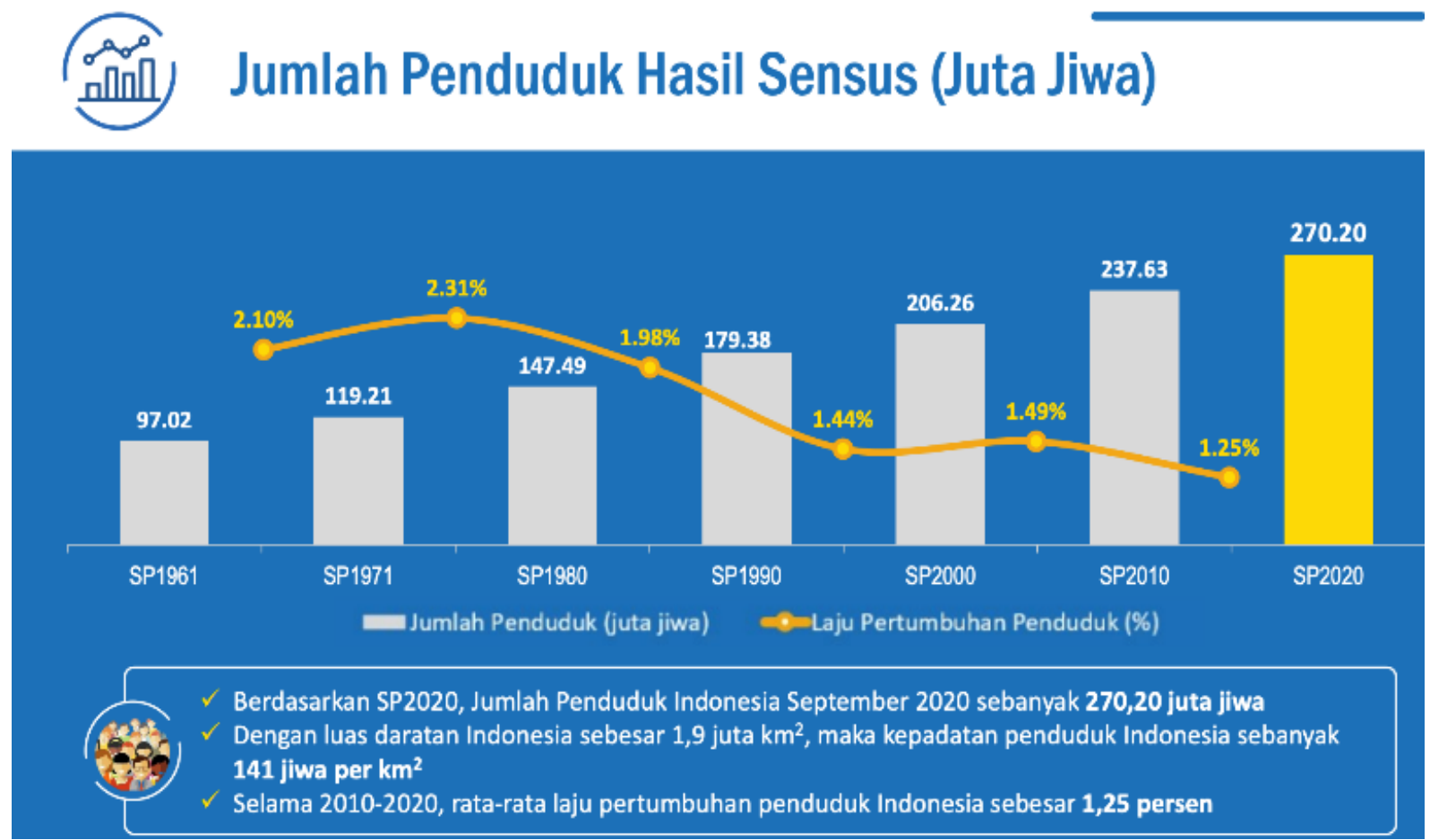

Gbr. 5 Pertumbuhan penduduk DKI Jakarta (sumber: bps.co.id).

Indonesia tinggal di Provinsi DKI Jakarta. Dari data-data tersebut juga dapat diketahui bahwa kepadatan penduduk di Provinsi DKI Jakarta sebanyak 15.906 jiwa per $\mathrm{km}^{2}$ sedangkan kepadatan penduduk di Indonesia hanya 141 jiwa per $\mathrm{km}^{2}$, yang artinya kepadatan penduduk di Provinsi DKI Jakarta adalah 118 kali lipat dibanding kepadatan penduduk di Indonesia. Tingkat kepadatan yang tinggi membuat arus mobilisasi penduduk dalam beraktivitas menjadi sangat kompleks sehingga kemacetan menjadi masalah utama yang timbul akibat kepadatan penduduk ini.

Selain itu, jika dilihat dari kondisi demografi usia penduduk Jakarta, seperti pada Gbr. 4, usia produktif mendominasi, yaitu $71 \%$ dari total jumlah penduduk Jakarta atau sebanyak 7.415.725 jiwa. Hal ini membuat tingkat mobilitas penduduk juga semakin tinggi karena didominasi oleh penduduk pada usia produktif, sehingga mobilitas yang tinggi menjadi salah satu urgensi masalah mobilitas penduduk di Jakarta.

Gbr. 5 menunjukkan pertumbuhan penduduk Jakarta selama tahun 2010-2020. Rata-rata laju pertumbuhan penduduk adalah sebesar 0,92 persen [20]. Sementara itu, pertumbuhan kendaraan bermotor dari tahun ke tahun sangat pesat, seperti yang ditunjukkan pada Gbr. 6. Peningkatan jumlah kendaraan bermotor ini tidak sebanding dengan pertumbuhan panjang jalan dan pembangunan infrastruktur. Dari analisis data tersebut, Jakarta perlu meningkatkan pertumbuhan panjang dan infrastruktur karena menjadi faktor yang krusial dalam pengembangan smart mobility. Namun, dengan kondisi kepadatan jumlah penduduk yang tinggi, yaitu sebesar 16.704 


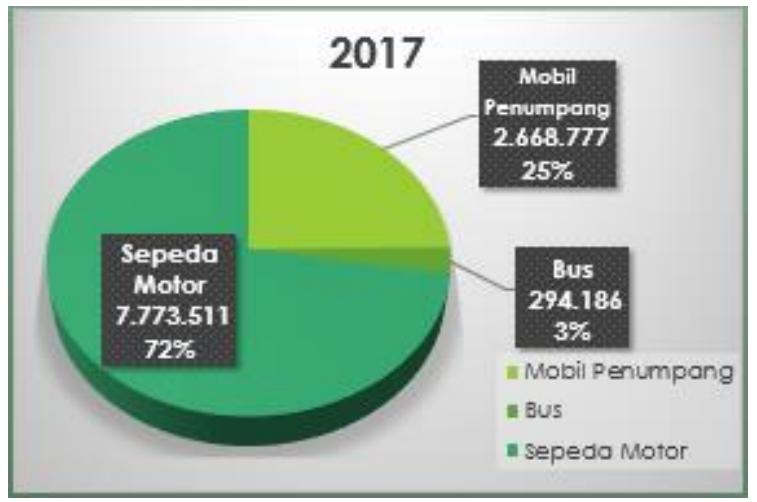

(a)

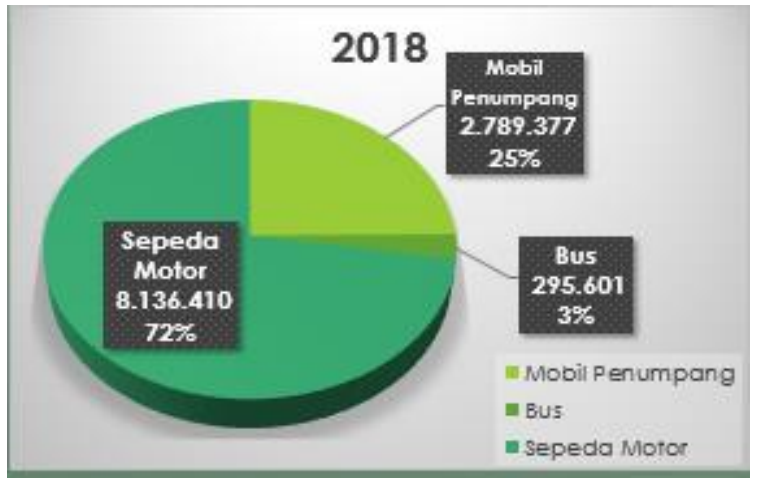

(b)

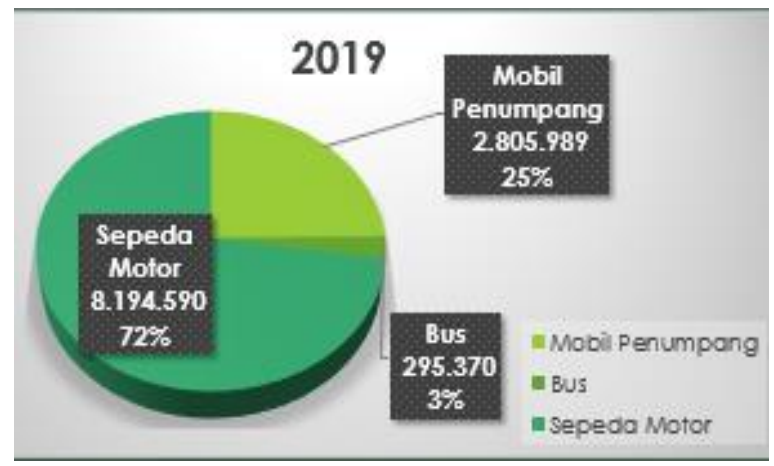

(c)

Gbr. 6 Jumlah kendaraan bermotor menurut jenis kendaraan (unit) di Provinsi DKI Jakarta (sumber: https://jakarta.bps.go.id/).

jiwa/ $/ \mathrm{km}^{2}$ [21], pembangunan infrastruktur jalan akan sulit dilakukan karena di samping lahan yang sudah sangat terbatas, juga tidak akan sebanding dengan jumlah peningkatan kendaraan bermotor pribadi. Solusi yang tepat adalah mendorong masyarakat untuk menggunakan transportasi publik.

Pertama, sisi ICT dapat dijelaskan dari dua aspek sebagai berikut.

1) Ketersediaan Sistem Smart Card: Berdasarkan data yang diperoleh dari aspek smart card, di Jakarta telah ada sistem smart card untuk mendukung pembayaran transportasi umum seperti yang ditunjukkan pada Gbr. 7. Sistem smart card untuk pembayaran sudah terintegrasi dengan berbagai moda transportasi. Pembayaran hanya dapat dilakukan dengan

\section{'e-mOney Te-mOney}
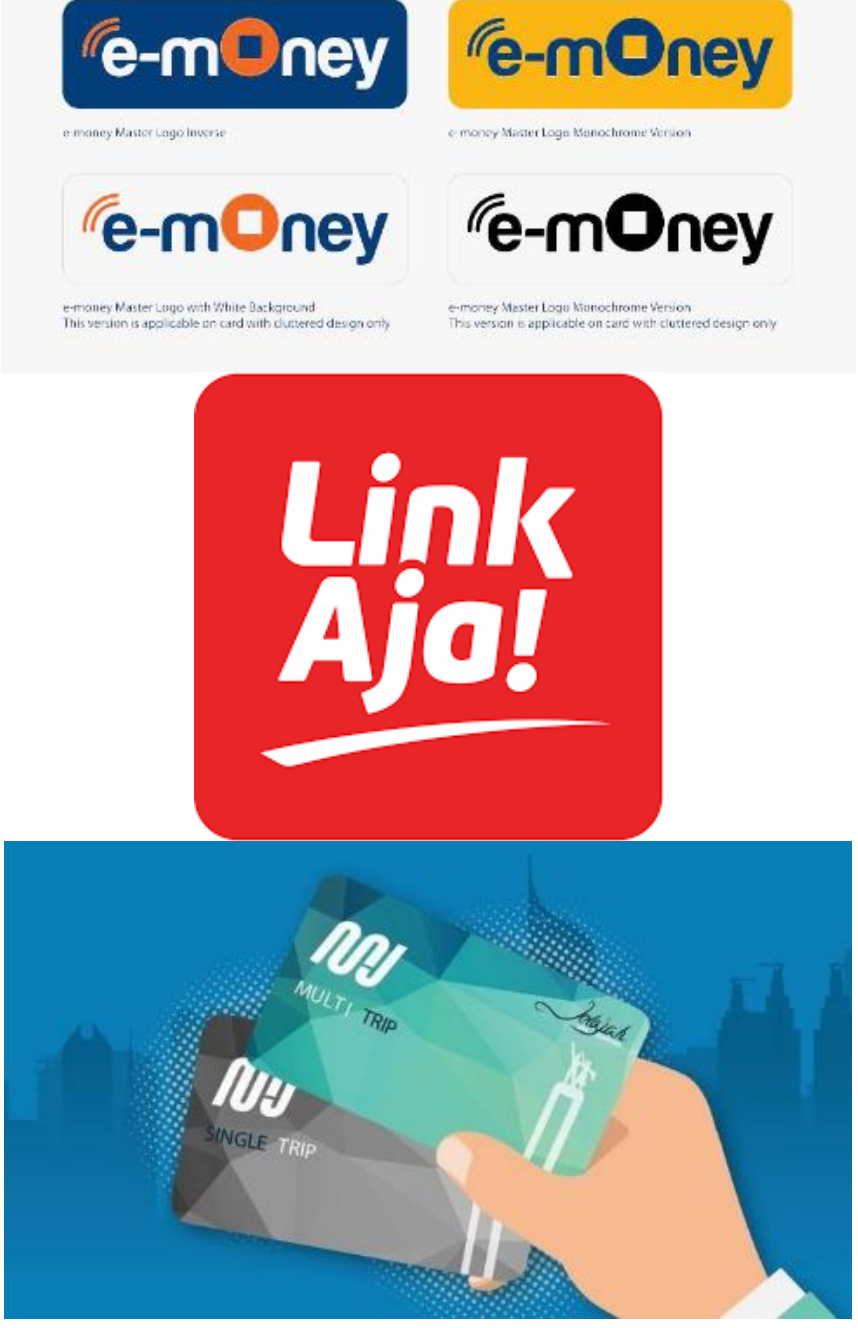

Gbr. 7 Sistem smart card untuk pembayaran transportasi umum di Jakarta (sumber: https://jakartamrt.co.id/id/metode-pembayaran\#).

menggunakan kartu elektronik yang dikeluarkan oleh bank di Indonesia dan dompet digital yang terintegrasi dengan aplikasi. Hal tersebut memudahkan penumpang dalam melakukan pembayaran serta mempercepat arus mobilisasi penumpang.

2) Ketersediaan Informasi Real Time: Smart mobility didukung oleh informasi real time, salah satunya mengenai informasi real time yang tersedia dari transportasi umum seperti yang ditunjukkan pada Gbr. 8. Di Jakarta sudah tersedia informasi real time dari transportasi umum seperti BRT maupun MRT yang dapat dilihat dari aplikasi masing-masing transportasi tersebut. Namun, masih ada kekurangan, yaitu aplikasi yang berbeda pada setiap moda transportasi. Hal tersebut menyebabkan ketidakpraktisan karena pengguna harus berganti aplikasi ketika menggunakan lebih dari satu moda transportasi. Ketersediaan informasi secara real time 


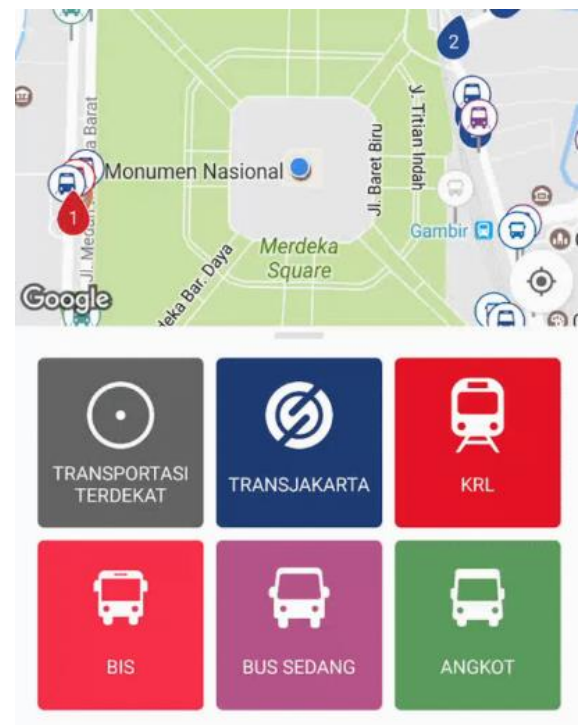

PETUNJUK ARAH

\section{Q Dapatkan petunjuk arah}

\section{A Tentukan lokasi rumah}

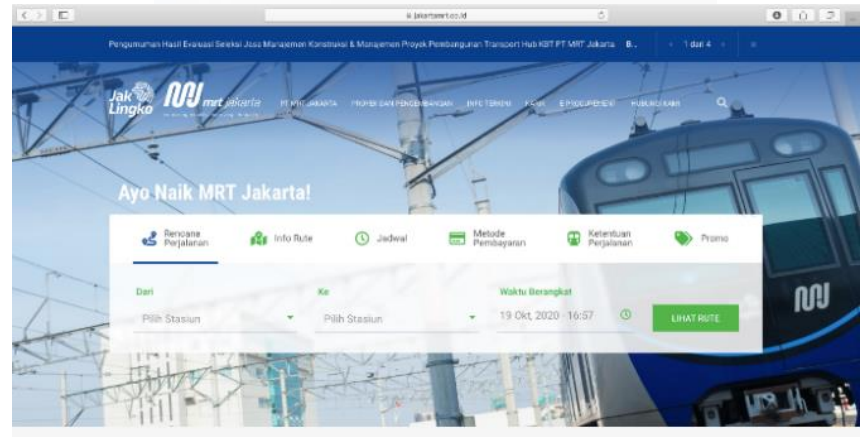

Info Terkini

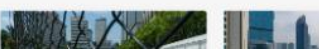

Gbr. 8 Informasi real time transportasi umum di Jakarta (sumber: https://jakartamrt.co.id/id/metode-pembayaran\#).

membantu penumpang dalam mengatur perjalanannya sehingga dapat meningkatkan efisiensi dalam mobilitas penduduk.

Dari aspek transportasi ramah lingkungan, diambil data dari bps.go.id berupa transportasi BRT (TransJakarta) menurut jenis bahan bakar yang diperoleh. Dari data jumlah TransJakarta menurut jenis bahan bakar yang diperoleh, yang ditunjukkan pada Gbr. 9, dapat dikatakan Jakarta belum siap karena diketahui dari sampel data bahwa jumlah TransJakarta yang menggunakan bahan bakar gas yang ramah lingkungan masih sedikit dibandingkan transportasi umum yang menggunakan bahan bakar premium. Selain itu, penggunaan bus barbahan bakar listrik belum diterapkan saat ini. Penggunaan transportasi yang ramah diperlukan untuk mendukung program Sustainable Development Goals (SDG).

Pengambilan data primer dilakukan menggunakan metode survei dengan jumlah responden 35 orang. Responden dalam

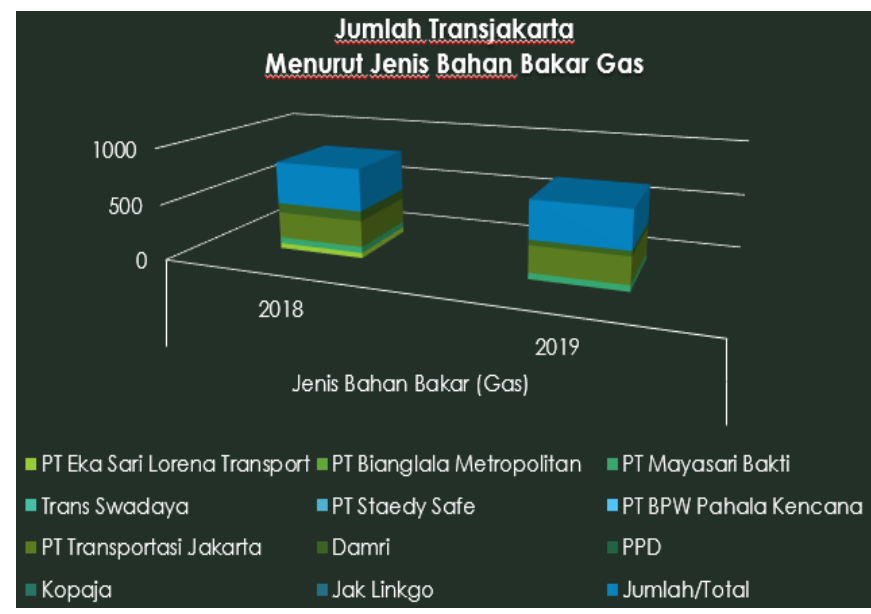

(a)

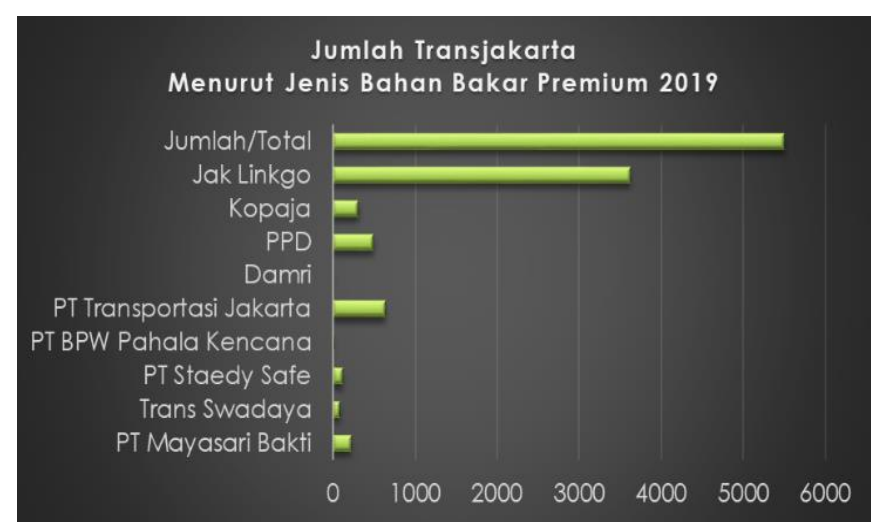

(b)

Gbr. 9 Jumlah TransJakarta (sumber: https://jakarta.bps.go.id/).

survei ini setiap harinya merupakan pengguna transportasi umum. Jumlah 35 responden diklaim sudah dapat mewakili populasi jumlah sampel. Kemudian, dengan memperhatikan enam dimensi dalam konsep smart city sebagai dasar penerapan smart city, yang salah satunya adalah smart mobility, terdapat empat indikator dalam smart mobility, yaitu:

- local accessibility,

- (inter-)national accessibility,

- availibility of ICT insfrastructure, dan

- sustainable, innovative, and safe transport system.

Parameter-parameter tersebut dijadikan sebagai indikator survei dalam melihat aspek kesiapan masing-masing indikator tersebut. Kemudian ringkasan hasil survei ditunjukkan pada Tabel I. Survei telah dilakukan oleh 35 responden dengan indikator aksesibilitas, penggunaan ICT, sustainability, serta keamanan dan kebersihan. Dari hasil survei didapatkan bahwa indikator-indikator tersebut berada pada rentang $48 \%$ sampai dengan $92,60 \%$.

\section{A. Tingkat Kesiapan Aksesibilitas dan Konektivitas}

Tingkat kesiapan aksesibilitas dan konektivitas lokal dilihat dari beberapa aspek, yaitu akses ke stasiun atau halte mudah dijangkau; beralih antarmoda transportasi cukup mudah; transportasi online seperti Gojek atau Grab selalu tersedia di 
TABEL I

RINGKASAN HASIL SURVEI

\begin{tabular}{|c|c|c|}
\hline Indikator & Deskripsi & Persentase \\
\hline \multirow{6}{*}{$\begin{array}{l}\text { Aksesibilitas dan } \\
\text { Konektivitas }\end{array}$} & $\begin{array}{l}\text { Akses ke stasiun/halte } \\
\text { mudah dijangkau }\end{array}$ & $63,00 \%$ \\
\hline & $\begin{array}{l}\text { Beralih ke antar moda } \\
\text { transportasi cukup } \\
\text { mudah }\end{array}$ & $73,10 \%$ \\
\hline & $\begin{array}{l}\text { Transportasi online } \\
\text { seperti Gojek/Grab } \\
\text { selalu tersedia di } \\
\text { sekitar stasiun }\end{array}$ & $82,00 \%$ \\
\hline & $\begin{array}{l}\text { Ongkos } \\
\text { LRT/MRT/KRL/BRT } \\
\text { cukup terjangkau }\end{array}$ & $92,60 \%$ \\
\hline & $\begin{array}{l}\text { Armada bus/kereta } \\
\text { MRT/LRT/KRL/BRT } \\
\text { berangkat tepat waktu }\end{array}$ & $48,10 \%$ \\
\hline & $\begin{array}{l}\text { Frekuensi kedatangan } \\
\text { LRT/MRT/KRL/BRT } \\
\text { cukup sering }\end{array}$ & $59,30 \%$ \\
\hline \multirow[t]{2}{*}{ ICT } & $\begin{array}{l}\text { MRT/LRT/KRL/BRT } \\
\text { telah memberikan } \\
\text { informasi mengenai } \\
\text { rute dan jadwal } \\
\text { keberangkatan dan } \\
\text { kedatangan melalui } \\
\text { aplikasi }\end{array}$ & $66,70 \%$ \\
\hline & $\begin{array}{l}\text { Membeli tiket atau } \\
\text { kartu pembayaran top- } \\
\text { up praktis dan mudah } \\
\text { dilakukan }\end{array}$ & $85,20 \%$ \\
\hline Sustainability & $\begin{array}{l}\text { Frekuensi transportasi } \\
\text { publik yang } \\
\text { menggunakan bahan } \\
\text { bakar ramah } \\
\text { lingkungan cukup } \\
\text { banyak }\end{array}$ & $51,90 \%$ \\
\hline \multirow{3}{*}{$\begin{array}{l}\text { Keamanan dan } \\
\text { Kebersihan }\end{array}$} & $\begin{array}{l}\text { Kenyamana ketika } \\
\text { menggunakan MRT/ } \\
\text { KRL/LRT/BRT baik } \\
\text { berdiri maupun duduk }\end{array}$ & $70,40 \%$ \\
\hline & $\begin{array}{l}\text { Kondisi di moda } \\
\text { transportasi } \\
\text { MRT/KRL/LRT/BRT } \\
\text { yang bersih }\end{array}$ & $81,50 \%$ \\
\hline & $\begin{array}{l}\text { Keamanan saat } \\
\text { menggunakan } \\
\text { MRT/KRL/LRT } \\
\end{array}$ & $66,70 \%$ \\
\hline
\end{tabular}

sekitar stasiun; ongkos LRT/MRT/KRL/BRT cukup terjangkau, armada bus/kereta MRT/LRT/KRL/BRT berangkat tepat waktu, dan frekuensi kedatangan LRT/MRT/KRL/BRT cukup sering. Dari aspek-aspek tersebut, data yang diperoleh dianalisis. Diperoleh persentase kepuasan pengguna terhadap aksesibilitas jaringan transportasi umum yang melayani wilayah Jakarta berada pada rentang 59,30\%-92,60\%. Namun, ketepatan waktu dan frekuensi kedatangan menjadi hal yang perlu ditingkatkan lagi. Jika dimasukkan ke dalam indeks kesiapan, nilai tersebut masuk pada kategori menuju siap, yang memiliki nilai presentase jaringan transportasi umum yang melayani kota sebesar $>66 \%$ [22]. Sementara itu, dilihat dari aspek kepuasan terhadap akses transportasi umum, nilai tersebut masuk kategori sangat siap [23], [24].

\section{B. Tingkat Kesiapan dan Experience Pengguna Transportasi Umum terhadap Infrastruktur Teknologi Informasi dan Komunikasi}

Tingkat kesiapan ICT dilihat dari beberapa aspek, yaitu MRT/LRT/KRL/BRT telah memberikan informasi mengenai rute dan jadwal keberangkatan dan kedatangan melalui aplikasi serta pembelian tiket atau top-up kartu pembayaran praktis dan mudah dilakukan. Dari data yang diperoleh dari survei pada tingkat kesiapan ICT, dapat dikatakan Jakarta sudah siap dan memberikan pelayanan yang baik terhadap pengguna transportasi karena data survei menunjukkan bahwa sebanyak 66,70\% responden setuju bahwa MRT/LRT/KRL/BRT telah memberikan informasi mengenai rute dan jadwal keberangkatan dan kedatangan melalui aplikasi. Kemudian, sebanyak $85,20 \%$ responden setuju bahwa pembelian tiket atau top-up kartu pembayaran praktis dan mudah dilakukan. Dalam smart mobility readiness levels untuk ICT, nilai ini masuk kategori siap [24].

\section{Tingkat Kesiapan Transportasi Berkelanjutan}

Salah satu aspek dari tingkat kesiapan transportasi berkelanjutan adalah aspek mobilitas hijau. Menurut data sekunder yang diperoleh dari bps.co.id, berdasarkan jumlah Transjakarta menurut jenis bahan bakar yang diperoleh, dapat dikatakan Jakarta belum siap dalam aspek mobilitas umum yang sudah menggunakan energi bersih. Hal ini disebabkan dari sampel data yang diperoleh, jumlah TransJakarta yang menggunakan bahan bakar gas yang ramah lingkungan masih sedikit. Data survei yang diperoleh juga sebanding dengan data sekunder, yang menyatakan bahwa persentase jumlah transportasi publik yang menggunakan bahan bakar ramah lingkungan adalah $51,9 \%$, sehingga tingkat kesiapan transportasi berkelanjutan Jakarta masuk kategori siap bersyarat (conditional ready) [24].

\section{Tingkat Keamanan dan Kebersihan}

Tingkat keamanan dan kebersihan transportasi publik di Jakarta dalam pengambilan data survei dilihat dari tiga aspek, yaitu kenyaman ketika menggunakan MRT/KRL/LRT/BRT, baik berdiri atau duduk; kondisi di moda transportasi MRT/KRL/LRT/BRT yang bersih; dan keamanan saat menggunakan moda transportasi MRT/KRL/LRT/BRT. Kemudian, dari penilaian responden terhadap ketiga aspek tersebut, diperoleh penilaian dengan rentang persentase 66,70\%-81,50\%. Dari penilaian yang dihasilkan, dapat disimpulkan bahwa tingkat keamanan dan kebersihan transportasi publik MRT/KRL/LRT/BRT sudah tinggi. Oleh karena itu, kesiapan keamanan dan kebersihan transportasi umum masuk tahap siap bersyarat sehingga perlu ada peningkatan dan perbaikan dari yang sudah ada saat ini [24].

\section{KESIMPULAN}

Berdasarkan karakteristik yang telah dianalisis pada masingmasing aspek smart mobility di Jakarta mengenai tingkat kesiapan yang didapat dari data sekunder maupun primer, 
penerapan smart mobility di Jakarta masih tergolong dalam kategori siap bersyarat. Pada dasarnya, Jakarta dapat dikatakan sudah siap dalam penerapan smart mobility pada aspek aksesibilitas dan konektivitas serta penggunaan teknologi informasi dan komunikasi, tetapi syarat-syarat perbaikan dan pengadaan di beberapa aspek smart mobility, terutama dalam aspek transportasi berkelanjutan dan infrastruktur fisik, perlu ditingkatkan.

\section{REFERENSI}

[1] (2017) "What is a Smart City? CNBC Explains" [Online], https://www.youtube.com/watch?v=bANfnYDTzxE, tanggal akses: 1Apr-2021.

[2] (2020) "Smart City Index 2020" [Online], https://www.imd.org/smartcity-observatory/smart-city-index/, tanggal akses: 2-Mar-2021.

[3] Y.S. Wicaksono dan M. Harahap, "Analysis of Travel Time and Bus Utilization of Corridor 1 Trans Jakarta to Realize the Smart Mobility Concept," Adv. in Econ., Bus., and Manag. Res., Vol. 72, hal. 345-352, 2019.

[4] E.P. Astutik dan Gunartin, "Analisis Kota Jakarta sebagai Smart City dan Penggunaan Teknologi Informasi dan Komunikasi Menuju Masyarakat Madani," Inovasi, Vol. 6, No. 2, hal. 41-58, 2019.

[5] R. Battarra, F. Zucaro, dan M.R. Tremiterra, "Smart Mobility: An Evaluation Method to Audit Italian Cities," 2017 5th IEEE Int. Conf. on Models and Technol. for Intel. Transport. Sys. (MT-ITS), 2017, hal. 421426.

[6] (2020) "Jakarta Smart City" [Online], http://interactive.smartcity. jakarta.go.id/, tanggal akses: 1-Mar-2021.

[7] (2020) "Jakarta - Smart Mobility" [Online], https://www.youtube.com/ watch?v=JDfCb9hLGPw\&t=499s, tanggal akses: 25 Mar-2021.

[8] (2019) "Metode Pembayaran" [Online], https://jakartamrt.co.id/id/ metode-pembayaran\#, tanggal akses: 21-Apr-2021.

[9] (2019) "Transjakarta dalam Angka 2019" [Online] https://ppid.transjakarta.co.id/pusat-data/infografis/24, tanggal akses: 19-Mar-2021.

[10] (2018) "Seluk-beluk Perjalanan 'Smart City" [Online], https://www.youtube.com/watch?v=RxwfIe3f8vw, tanggal akses: 28Mar-2021.

[11] A. Orlowski, "Smart Cities Concept: Smart Mobility Indicator," Cybernetics and Systems, Vol. 50, No. 2, hal. 118-131, 2018.
[12] F. Anindra, "Smart City Implementation Modelling in Indonesia with Integration Platform Approach," 2018 Int. Conf. on Inform. Manag. and Technol. (ICIMTech), 2018, hal. 43-48.

[13] S. Agam (2017) "Jakarta Perintis 100 Smart City" [Online] http://indonesiabaik.id/, tanggal akses: 2-Mar-2021.

[14] S. Rhee, "Catalyzing the Internet of Things and Smart Cities: Global City Teams Challenge," 1st Int. Work. on Sci. of Smart City Op. and Platforms Eng. (SCOPE) in partnership with Glob. City Teams Challenge (GCTC) (SCOPE - GCTC)), 2016, hal. 1-4.

[15] F. Basbeth, U. Sedyowidodo, dan A. Sumanto, "Mobile Application and Smart City Orientation: The Moderating Role of Tech Savvy Population," Int. Conf. on ICT for Smart Soc. (ICISS), 2019, hal. 1-4.

[16] (2020) "TomTomTrafficIndex-Ranking-2020" [Online], https://www.tomtom.com/en_gb/traffic-index/jakarta-traffic/, tanggal akses: 14-Mar-2021.

[17] (2018) "Statistik Transportasi DKI Jakarta 2018" [Online], https://jakarta.bps.go.id/, tanggal akses: 23-Apr-2021.

[18] (2021) "Pemerintah Provinsi DKI Jakarta" [Online] https://jakarta.bpk.go.id/, tanggal akses: 14-Mar-2021.

[19] (2015) "Konsep Smart City: Smart Mobility" [Online], http://yulhendri.weblog.esaunggul.ac.id/wpcontent/uploads/sites/5361/2 015/12/smart_city___konsep_smart_mobility.pdf, tanggal akses: 23-Apr2021.

[20] (2020) "Hasil Sensus Penduduk 2020" [Online], https://jakarta.bps.go.id/, tanggal akses: 22-Apr-2021.

[21] (2020) "Portal Statistik Sektoral Provinsi DKI Jakarta" [Online], https://statistik.jakarta.go.id/berapa-kepadatan-penduduk-dki-jakartasaat-ini, tanggal akses: 22Apr-2021.

[22] A. Pratiwi, Soedwiwahjono, dan A. Hardiana, "Tingkat Kesiapan Kota Surakarta terhadap Dimensi Mobilitas Cerdas (Smart Mobility) sebagai Bagian dari Konsep Kota Cerdas (Smart City)," Region, Vol. 6, No. 2, hal. 34-41, 2015 .

[23] Indrawati, N.N. Aini, dan H. Amani "Indicators to Measure Smart Mobility: An Indonesian Perspective," Proc. 2017 Int. Conf. on Telecom. and Commun. Eng. (ICTCE '17), 2017, hal. 81-85.

[24] H.I. Sunardi, S. Sulistyo, dan I.W. Mustika, "Analysis of Smart Mobility Readiness in Banjarmasin City," Proc. Int. Conf. on Creative Econ., Tourism and Inf. Manag. (ICCETIM 2019), 2019, hal. 158-162. 